\title{
EST sequencing and SSR marker development from cultivated peanut (Arachis hypogaea L.)
}

\section{Guo Qi Song}

High-Tech Research Center

Shandong Academy of Agricultural Sciences

Key Laboratory for Genetic Improvement of Crop, Animal and Poultry of Shandong Province

Key Laboratory of Crop Genetic Improvement and Biotechnology, Huanghuaihai Ministry of Agriculture, Ji'nan 250100, People's Republic of China

\section{Meng Jun Li}

High-Tech Research Center

Shandong Academy of Agricultural Sciences

Key Laboratory for Genetic Improvement of Crop, Animal and

Poultry of Shandong Province

Key Laboratory of Crop Genetic Improvement and Biotechnology, Huanghuaihai Ministry of Agriculture, Ji'nan 250100, People's Republic of China

\section{Han Xiao}

High-Tech Research Center

Shandong Academy of Agricultural Sciences

Key Laboratory for Genetic Improvement of Crop, Animal and Poultry of Shandong Province

Key Laboratory of Crop Genetic Improvement and Biotechnology, Huanghuaihai Ministry of Agriculture, Ji'nan 250100, People's Republic of China

\section{Xing Jun Wang*}

High-Tech Research Center

Shandong Academy of Agricultural Sciences

Key Laboratory for Genetic Improvement of Crop, Animal and Poultry of Shandong Province

Key Laboratory of Crop Genetic Improvement and Biotechnology, Huanghuaihai Ministry of Agriculture, Ji'nan 250100, People's Republic of China

E-mail: xingjunw@hotmail.com

\section{Rong Hua Tang}

Cash Crops Research Institute

Guangxi Academy of Agricultural Sciences

Nan'ning 530007, People's Republic of China

\section{Han Xia}

High-Tech Research Center

Shandong Academy of Agricultural Sciences

Key Laboratory for Genetic Improvement of Crop, Animal and Poultry of Shandong Province

Key Laboratory of Crop Genetic Improvement and Biotechnology, Huanghuaihai Ministry of Agriculture, Ji'nan 250100, People's Republic of China

\section{Chuan Zhi Zhao}

High-Tech Research Center

Shandong Academy of Agricultural Sciences

Key Laboratory for Genetic Improvement of Crop, Animal and Poultry of Shandong Province

Key Laboratory of Crop Genetic Improvement and Biotechnology, Huanghuaihai Ministry of Agriculture, Ji'nan 250100, People's Republic of China

\section{Yu Ping Bi}

High-Tech Research Center

Shandong Academy of Agricultural Sciences

*Corresponding author 


\author{
Key Laboratory for Genetic Improvement of Crop, Animal and \\ Poultry of Shandong Province \\ Key Laboratory of Crop Genetic Improvement and Biotechnology, Huanghuaihai \\ Ministry of Agriculture, Ji'nan 250100, People's Republic of China
}

Keywords: Arachis hypogaea L., cultivars, EST-SSR, polymorphism, wild-type peanut.

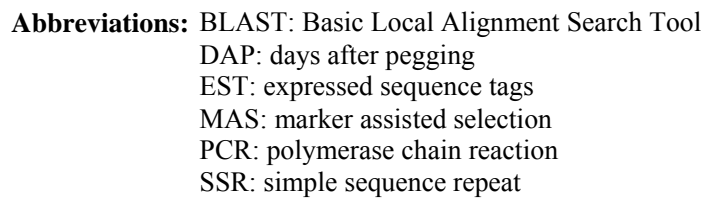

Making use of the gene resources of wild type peanuts is a way to increase the genetic diversity of the cultivars. Marker assisted selection (MAS) could shorten the process of inter-specific hybridization and provide a possible way to remove the undesirable traits. However, the limited number of molecular markers available in peanut retarded its MAS process. We started a peanut ESTs (Expressed Sequence Tags) project aiming at cloning genes with agronomic importance and developing molecular markers. In this study we found 610 ESTs that contained one or more SSRs from 12,000 peanut ESTs. The most abundant SSRs in peanut are trinucleotides $(66.3 \%)$ SSRs and followed by dinucleotide (28.8\%) SSRs. AG/TC (10.7\%) repeat was the most abundant and followed by CT/GA $(\mathbf{9 . 0 \%})$, CTT/GAA (7.4\%), and AAG/TTC (7.3\%) repeats. Ninety-four SSR containing ESTs were randomly selected for primer design and synthesis, of which 33 pairs could generate good amplification and were used for polymorphism assessment. Results showed that polymorphism was very low in cultivars, while high level of polymorphism was revealed in wild type peanuts.

Peanut is one of the most important oil seed crops in the world, cultivated mainly in tropical, subtropical and warm temperate climates (Proite et al. 2007). The cultivated peanut is an allotetraploid (AABB, $2 n=4 x=40$ ), originated from chromosome duplication of hybrid between AA and BB wild type species, which happened about 3500 years ago. Polyploidy and self-pollination nature of this species blocked the genetic exchange between the cultivated and the wild type species which lead to limited genetic diversity of the major cultivars. Using of only very few central germplasms in breeding programs further limited the addition of genes with agronomic value. Due to its limited genetic variation peanuts are vulnerable to a wide variety of pathogens and abiotic stresses. For example, fungal foliar diseases of peanut such as rust, web blotch, and leaf spot cause severe loss of yield worldwide (Leal-Bertioli et al. 2009).

Wild type peanuts are genetically very diverse and selectively accumulated biotic and abiotic stress resistant genes during their adaptation to different harsh environments (Holbrook and Stalker, 2003). However, hybrids between the diploid wild type and the allotetraploid cultivated peanut are sterile (Tallury et al. 2005). In order to obtain tetraploid fertile offspring of the diploid wild type and the allotetraploid cultivated peanut, complicated breeding programs have to be designed. It normally takes many years to get a hybrid with agronomical value (Simpson et al. 1993; Stalker and Beute, 1993; Simpson and Starr, 2001). Marker assisted selection could increase the efficiency and predictability during the process of wild gene pool utilization. However, it was retarded by the small number of peanut molecular markers and the unavailability of high density linkage map (Burow et al. 2001; Moretzsohn et al. 2005). The attempt to develop more peanut molecular markers for construction of high density linkage map is of great importance. Microsatellites (SSRs) as DNA markers are highly polymorphic, highly abundant, show co-dominant inheritance, analytically simple and readily transferable between different plant species (He et al. 2003). Previous studies showed that SSR markers could detect more polymorphism in peanut than other molecular markers like RFLPs (Gimenes et al. 2007), AFLPs (He and Prakash, 2001; Gimenes et al. 2002) and RAPDs (Dwivedi et al. 2001; Subramanian et al. 2000).

Beside sequencing SSR enriched genomic library for SSR marker development (He et al. 2003; Han et al. 2006), searching SSRs using peanut EST information is an alternative way for marker discovery (Wang et al. 2006; Proite et al. 2007; Liang et al. 2009). We started an EST project using immature peanut seeds cDNA library of a Chinese cultivar to generate more sequence information for gene cloning ( $\mathrm{Li}$ et al. 2009, Li et al. 2010) and marker development. The objectives of the present study were to develop more SSR markers from peanut using these EST sequences, and to detect the polymorphisms of the newly identified SSR markers in a collection of cultivated and wild type peanut accessions. The resulted SSR markers especially those showed polymorphism in different peanuts accessions would be valuable for peanut marker linkage map construction and marker assisted selection in the future. 


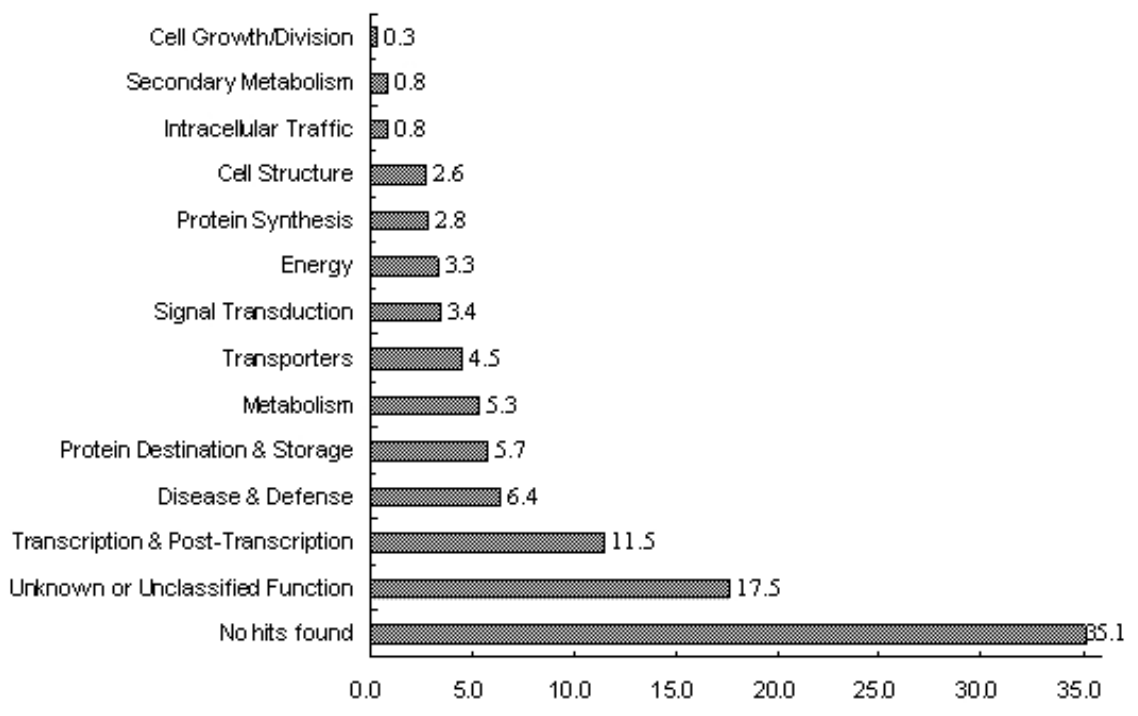

Percentage of ESTs per category

Figure 1. Percentage and functional categories of SSR containing ESTs.

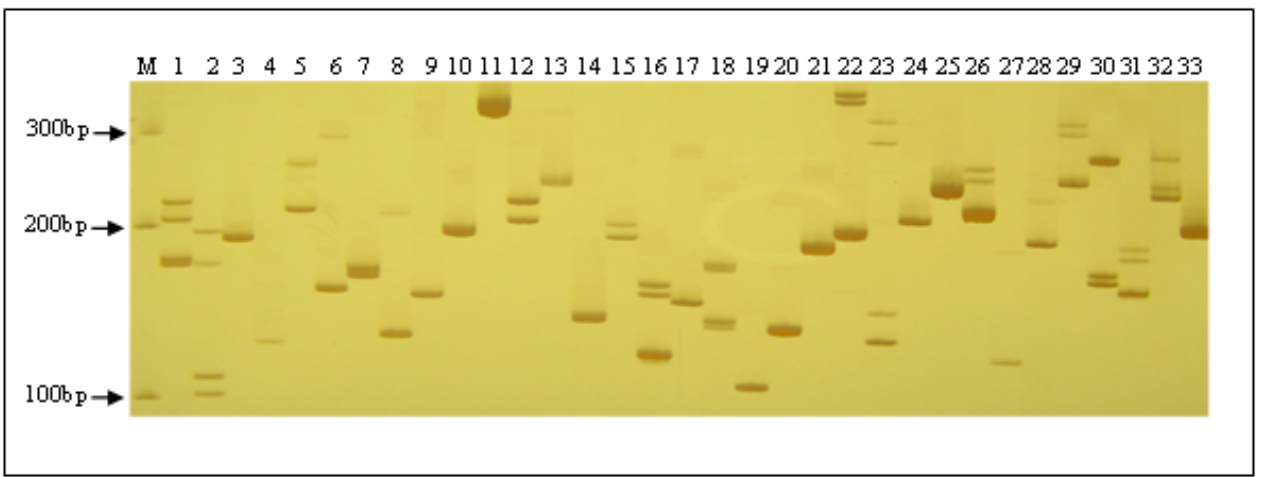

Figure 2. The amplification results of 33 pairs of primer using cultivated peanut Luhua-14. M, DNA marker; lanes 1 to 33 , primer pairs of F2, F3, F9, F13; PD10, PD11, PD15, PD17, PD18, PD19, PD20, PD23, PD28, PD33, PD35, PD36, PD37, PD38, PD40, PD49, PD52, PD54, PD59; H2, H4, H6, H7, H8, H10, H11, H13, H14, H15.

\section{MATERIALS AND METHODS}

\section{Plant material}

Luhua-14 peanut used for cDNA library construction was obtained from Shandong Academy of Agricultural Sciences. A total of 98 accessions of wild type and cultivated peanuts were examined in this study. Twentyfive accessions belonging to section Arachis or Heteranthae which come from Nanning branch of the national wild peanut germplasm resource were used for polymorphism assessment. Seventy-three accessions belonging to cultivated species were used for genetic diversity analysis. Of these, fifty-six were collected from different provinces and the other 17 were from Wuhan national peanut germplasm resource belonging to var. fastigiata, var. hirsuta, var. hypogaea and var. vulgaris (Table 1 and Table 2).

\section{Peanut cDNA library construction}

The peanut seeds of different growing stages ranging from 20 to 60 DAP (days after pegging) were collected and placed into liquid $\mathrm{N}_{2}$ immediately and stored in $-80^{\circ} \mathrm{C}$ freezer. RNA was extracted using RNAgent kit (Promega) according to the manufacturer's instructions. The quantity and quality of RNA was evaluated by spectrophotometry and agarose gel electrophoresis. cDNA synthesis and library construction followed the protocol of Stratagene's pBluescript II cDNA library construction kit. 
Song, G.Q. et al.

\section{Sequencing and ESTs analysis}

Plasmid DNA was isolated from the randomly selected colonies and preserved in 96-well plate. Plasmid DNA was used as template for PCR amplification using T3 and T7 universal primers. PCR products were purified using AxyPrep $^{\mathrm{TM}}$ PCR Cleanup Kit (AXYGEN), and sequenced using BigDye Terminator Cycle Sequencing Kit. Sequencing was performed on 3730XL Sequencer (ABI) using T3 or T7 primers. Sequences were edited by the software SEQENCHER and vector sequences were trimmed manually.

\section{Analysis of microsatellites and primer design}

EST sequences were searched for SSRs using SSR tool software (http://www.gramene.org/db/searches/ssrtool) to identify di- and trinucleotide and tetranucleotide SSR motifs. SSR motifs repeated more than five times in dinucleotide, four times in trinucleotide and tetranucleotide

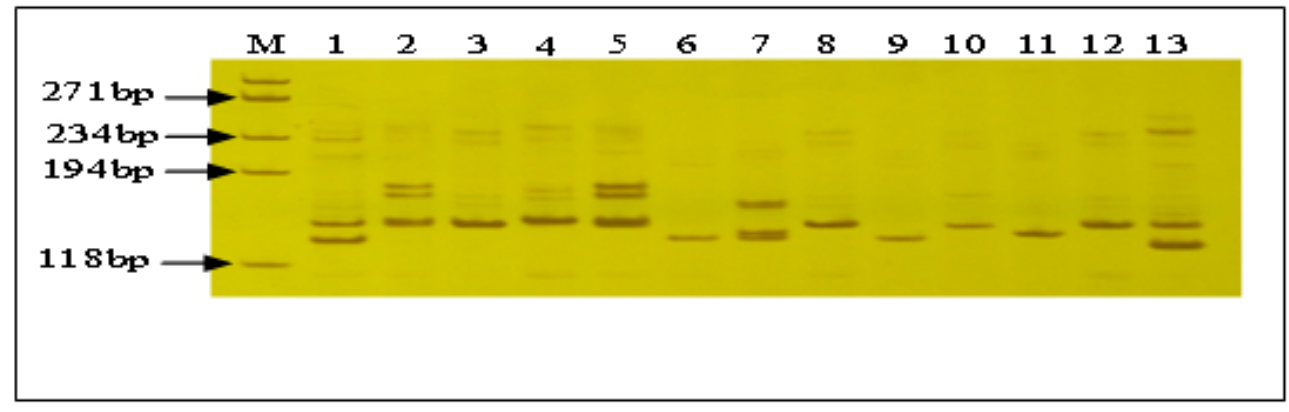

Figure 3. Polymorphism revealed by PD59 SSR maker in wild type peanuts. M, DNA Marker; lanes 1 to 12 , wild type peanuts; lane 13, cultivated peanut Luhua-14.

Table 1. The accessions used for DNA polymorphism detection which came from Wuhan national peanut germplasm resource.

\begin{tabular}{|c|c|c|c|}
\hline No. & Type & Cultivar & Origin \\
\hline 1 & \multirow{3}{*}{ var. fastigiata } & PI393531 & America \\
\hline 2 & & Qiongshan Huasheng & China \\
\hline 3 & & Liaoning Silihong & China \\
\hline 4 & \multirow{4}{*}{ var. hirsuta } & Daye Pingtianzi & Jiang $x i$ \\
\hline 5 & & Yingde Jidouzai & China \\
\hline 6 & & Jintang Shenwozi & Si chuan \\
\hline 7 & & Tuokexun Xiaohuasheng & China \\
\hline 8 & \multirow{5}{*}{ var. hypogaea } & Yangjiang Pudizhan & China \\
\hline 9 & & Xihua Goudou & China \\
\hline 10 & & Padou & China \\
\hline 11 & & Zhuzaidou & China \\
\hline 12 & & Yingde Zhusidou & China \\
\hline 13 & \multirow{5}{*}{ var. vulgaris } & Dedou & China \\
\hline 14 & & Bairizai & China \\
\hline 15 & & Guangliu & China \\
\hline 16 & & Sanyuening & China \\
\hline 17 & & Dingzi Xili & China \\
\hline
\end{tabular}




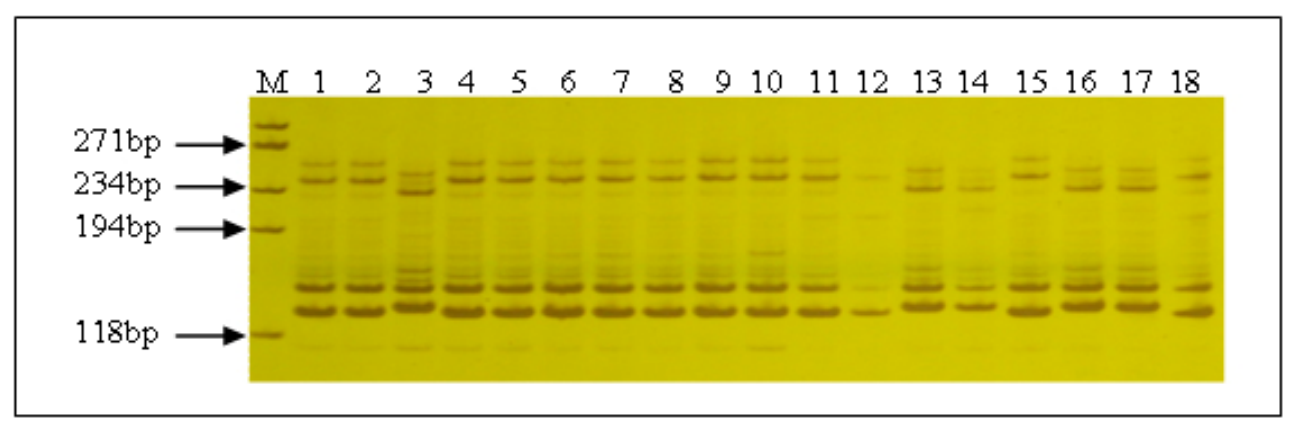

Figure 4. Polymorphism revealed by PD59 SSR maker in peanut cultivars. M, DNA Marker; lanes 1 to 18, cultivars PI393531, Qiongshan Huasheng, Liaoning Silihong, Daye Pingtianzi, Yingde Jidouzai, Jintang Shenwozi, Tuokexun Xiaohuasheng, Yangjiang Pudizhan, Xihua Goudou, Padou, Zhuzaidou, Yingde Zhusidou, Dedou, Bairizai, Guangliu, Sanyuening, Dingzi Xili, and Luhua-14.

Table 2. The accessions used for DNA polymorphism detection which collected from different provinces.

\begin{tabular}{|c|l|c|l|c|l|}
\hline NO. & \multicolumn{1}{|c|}{ Cultivar } & NO. & \multicolumn{1}{|c|}{ Cultivar } & NO. & \multicolumn{1}{|c|}{ Cultivar } \\
\hline 1 & Huayu 16 & 20 & Jinhua 1012 & 39 & Yueyou 92 \\
\hline 2 & Huayu 17 & 21 & Guihua 17 & 40 & Trifumer \\
\hline 3 & Huayu 19 & 22 & Heyou 4 & 41 & Hua 27 \\
\hline 4 & Huayu 21 & 23 & Yueyou 551 & 42 & Xuxi 1 \\
\hline 5 & Huayu 22 & 24 & Quanhua 327 & 43 & Xuhua 3 \\
\hline 6 & Huayu 23 & 25 & Luhua 9 & 44 & FT001 \\
\hline 7 & Luhua 10 & 26 & Hua 17 & 45 & Luhua 2 \\
\hline 8 & Luhua 11 & 27 & AR-2 & 46 & Luhua 12 \\
\hline 9 & Fenghua 1 & 28 & Dayingzui & 47 & FT002 \\
\hline 10 & Fenghua 5 & 29 & FT004 & 48 & 616 \\
\hline 11 & Zhufeng 1 & 30 & Furonghuasheng & 49 & FT005 \\
\hline 12 & Qinglan 2 & 31 & Yuhua 15 & 50 & Haihua 1 \\
\hline 13 & Weihua 6 & 32 & Quanhua 646 & 51 & FT003 \\
\hline 14 & Shuangji 22 & 33 & AR-3 & 52 & Yueyou 116 \\
\hline 15 & Heihuasheng & 34 & GFA-1 & 53 & FN006 \\
\hline 16 & Baisha 1016 & 35 & Quanhua 10 & 54 & Jihua 2 \\
\hline 17 & Minhua 5 & 36 & Yuhua 14 & 55 & Yuhua 10 \\
\hline 18 & Minhua 6 & 37 & HSO02 & 56 & Luhua-14 \\
\hline 19 & Minhua 10 & 38 & GFA-2 & & \\
\hline & & & & & \\
\hline
\end{tabular}

were counted. Primers were designed using Primer 5 software.

\section{DNA extraction and PCR amplification}

Seventy-three cultivated peanuts and 25 wild type peanuts were used for polymorphism study. Genomic DNA was extracted from young leaf tissue using CTAB method (Murray and Thompson, 1980). DNA concentration was 
determined by spectrophotometer. PCR mixture consisted of 1X PCR buffer, $200 \mu \mathrm{M}$ of each dNTP, 1U Taq polymerase (TaKaRa) and $0.5 \mu \mathrm{M}$ of each primer and 40 $60 \mathrm{ng}$ of template DNA. The thermocycling conditions started with $94^{\circ} \mathrm{C}$ for $5 \mathrm{~min}, 10$ cycles of $94^{\circ} \mathrm{C}$ for $45 \mathrm{sec}$, $\mathrm{X}^{\circ} \mathrm{C}$ for $45 \mathrm{sec}, 72^{\circ} \mathrm{C}$ for $45 \mathrm{sec}$, and then 30 cycles of $94^{\circ} \mathrm{C}$ for $45 \mathrm{sec}, \mathrm{Y}^{\circ} \mathrm{C}$ for $45 \mathrm{sec}, 72^{\circ} \mathrm{C}$ for $45 \mathrm{sec}$ followed by a terminal extension step of $72^{\circ} \mathrm{C}$ for $10 \mathrm{~min}$. The annealing temperatures ( $\mathrm{X}$ and $\mathrm{Y}$ ) were optimized for each primer to allow the best amplification (Table 3). Amplification products were visualized on $6.5 \% \mathrm{w} / \mathrm{v}$ denaturing polyacrylamide gels (19:1 acrylamide/bisacrylamide, $7 \mathrm{M}$ urea) that were silver stained (Gao et al. 2009). Product size was estimated based on $\Phi \times 174-H a e I I I$ digest DNA Marker (TaKaRa) or Bio DL100 (Bio Flux).

\section{RESULTS AND DISCUSSION}

\section{Sequence analysis and SSR identification}

A cDNA library was constructed using mRNA from immature seeds at different developmental stages of cultivated peanut Luhua-14. The insert length of the library ranged from 500-1500 bp with an average length of $900 \mathrm{bp}$ based on PCR results for $>1000$ randomly picked colonies (data not shown). Sequences were edited by the software SEQENCHER and vector sequences were removed manually. Short sequences $(<200 \mathrm{bp})$ and sequences with many unreadable nucleotides were discarded. 12,000 ESTs with good quality including the 7,456 ESTs deposited to GenBank (EE123340-EE127745; EG372473-EG374270; EG529454-EG530705) were subjected for SSR discovery. From these ESTs 610 SSR containing sequences were identified. A homology search against NCBI protein database was conducted by BLASTX with an E value of 0.02 as the cut-off threshold. Based on the BLAST results 610 SSR containing ESTs were grouped into 14 categories (Figure 1). More than half of these ESTs have no hits $(35.1 \%)$ and corresponding unknown proteins $(17.5 \%)$ in the database. The third largest functional category $(11.5 \%)$ was transcription and post-transcription related factors, followed by disease and defense (6.4\%), protein destination and storage (5.7\%) and metabolism (5.3\%) related genes.

Among 610 SSR-containing ESTs, 436 (71.5\%) contained single SSR, $132(21.6 \%)$ contained two SSRs, and the rest (6.9\%) contained more than two SSRs. Among 841 SSRs identified, $66.3 \%$ were trinucleotides, followed by dinucleotides $(28.8 \%)$, tetranucleotides $(3.2 \%)$, pentanucleotides $(0.8 \%)$, and hexanucleotides $(0.8 \%)$. $\mathrm{AG} / \mathrm{TC}$ was found to be the most common repeat motif (10.7\%), followed by CT/GA $(9.0 \%)$, CTT/GAA (7.4\%), AAG/TTC (7.3\%), AGA/TCT (6.2\%), and AT/TA repeat motifs (5.4\%). Previous surveys carried out on microsatellite abundance analysis in plant genomes have shown ATT and CTT were the most frequent trinucleotide repeat motifs (Lagercrantz et al. 1993; Ferguson et al. 2004), and AT was the most abundant dinucleotide repeat motif followed by AG/CT and GT/CA (Cuc et al. 2008; Han et al. 2006). He et al. (2003) found that GA/CT repeat was the most frequently dispersed microsatellite in peanut. Cuc and coworkers indicated that GT/CA repeat motif was the most common, accounting for $37.6 \%$ of all repeat types, followed by $\mathrm{GA} / \mathrm{CT}$ repeat at $25.9 \%$ (Cuc et al. 2008). From this it can be concluded that SSR motifs are not equally abundant in eukaryotic genomes and the relative abundance of different motifs varies among species (Wang et al. 1994; Han et al. 2006).

Cultivated peanut Luhua-14was used to analyze the amplification quality of the identified SSRs. All 33 (35.1\%) primer pairs with good amplification were selected for further analysis of polymorphism in different cultivars and wild type peanuts (Table 3, Figure 2).

\section{Polymorphism study of wild type and cultivated peanuts}

Twenty-five wild type peanuts were analyzed using the selected 33 SSR primer pairs. Most primer pairs could amplify distinct bands. However, some wild type peanuts failed to amplify any bands with some primer pairs. The possible reason for this result might due to the notable difference between wild type and cultivated peanuts.

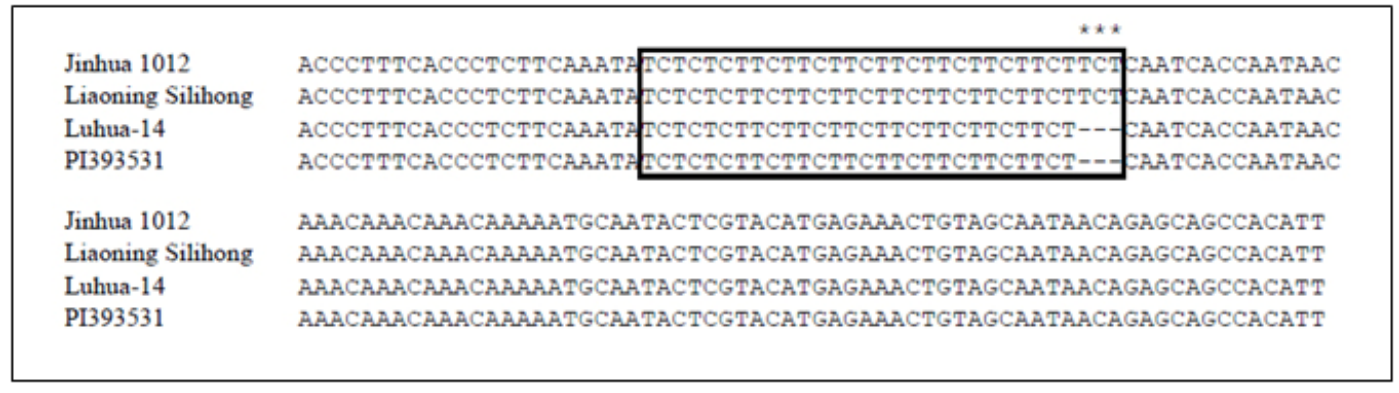

Figure 5. Sequences comparison of polymorphic bands in different cultivars: Luhua-14, PI393531, Liaoning Silihong, Jinhua1012. 
Table 3. Peanut microsatellite markers with good amplification quality in Luhua- 14.

\begin{tabular}{|c|c|c|c|c|c|c|}
\hline \multirow{2}{*}{$\begin{array}{l}\text { Primer } \\
\text { pair }\end{array}$} & \multirow{2}{*}{ Forward primer (5'-3') } & \multirow{2}{*}{ Reverse primer (5'-3') } & \multirow{2}{*}{ Motif } & \multicolumn{2}{|c|}{ Annealing } & \multirow{2}{*}{$\begin{array}{l}\text { Expected } \\
\text { Size (bp) }\end{array}$} \\
\hline & & & & $\mathrm{x}$ & $\mathrm{Y}$ & \\
\hline $\mathrm{F} 2$ & GGATTCATTCGAGGGTGG & AAGGCATCTTTGTCGTTG & (CTT)6 & 58 & 56 & 168 \\
\hline F3 & CAGCAACTTTCTTCAACC & СTCTGAATCTCGCACCCT & $(A G A) 6$ & 58 & 56 & 108 \\
\hline F9 & TTCGAGCTTGAGGAAGAG & AACGGAATTTGAGATGATAG & $($ AATC) 6 & 56 & 54 & 191 \\
\hline F13 & ATCCTACGATTTCTTTACTG & TCGATGGAGGGATGATTT & (CT)25 & 50 & 48 & 152 \\
\hline $\mathrm{H} 2$ & TCCCAGAACAACAATCAC & AGAAGAATACGAGCACCA & $(\mathrm{TCT}) 5$ & 54 & 52 & 215 \\
\hline $\mathrm{H} 4$ & TCTTGATCTTATCTTCCCTG & CAAATGTGGTGTCGCTGA & (TCA)5 & 56 & 54 & 244 \\
\hline $\mathrm{H} 6$ & CCAACTCGACTCGGCTTTC & TTGСTССТСТАACAАССТTTCT & (TC)7 & 56 & 54 & 221 \\
\hline $\mathrm{H} 7$ & CCTCACCAACCAGGATAC & TTTCGTCTTTGCAGTTTC & (CTT) 4 & 54 & 52 & 122 \\
\hline $\mathrm{H} 8$ & ATCAAGCCATAATATGTTCC & CAACCCAAGCACСТCTAC & (TA)6 & 54 & 52 & 193 \\
\hline $\mathrm{H} 10$ & AGAGTAAGGGTGCTTCTG & ATGCTTCTCCСАTTTCCA & (GAT)5 & 54 & 52 & 142 \\
\hline H11 & CCGAACTCAACCCAAACA & AGCTCCGGCAAGAAAGAA & (CAC)4 & 56 & 54 & 178 \\
\hline $\mathrm{H} 13$ & GCTTTTATTTCACATACATCAC & GGTAGGGCACTGTTCACTT & (CTT)7 & 54 & 52 & 165 \\
\hline $\mathrm{H} 14$ & ACGAAGCCTAAGAACGGAAAG & ATGCCACCAGCAAAGGAG & $(\mathrm{AC}) 5$ & 56 & 54 & 258 \\
\hline $\mathrm{H} 15$ & CGGTCGTAGTAGTTGTGG & GAGGCTTAAAGGAAGTGG & (CT) 6 & 56 & 54 & 216 \\
\hline PD10 & ACTTGCTTTGGATGCTTG & CTTTTCTTTTCCCGGACT & $($ TTA $) 7$ & 50 & 48 & 208 \\
\hline PD11 & СTCTTTCATTATTGGGTTTG & AGATTGTGCAGCCTCATC & $(\mathrm{TAA}) 7$ & 54 & 52 & 152 \\
\hline PD15 & ACTAACACCATTTCCGACAG & TGGGAGCCTATGAAACCT & $($ TTC $) 5$ & 58 & 56 & 163 \\
\hline PD17 & СTTTCCСАTATTCСTTCGT & TGTTCCTCCTCCTGCTTT & $(\mathrm{TCT}) 6$ & 56 & 54 & 129 \\
\hline PD18 & ATCATCATCATCATCGTC & AGTTTCTGGTACTGTCGC & $(\mathrm{TCA}) 6$ & 54 & 52 & 152 \\
\hline PD19 & CGTGGAGAACGTGCTTAG & CCATAGATCGAAATAGGTAG & $($ TTA $) 5$ & 54 & 52 & 210 \\
\hline PD20 & GAAGAAAATAGCAGGACT & CGTAGTATCTTGATAACCC & (CTT)6 & 56 & 54 & 254 \\
\hline PD23 & TACAATGTTGCCTTTCAC & СААСТССТСАСТАСТССС & (TAA)6 & 56 & 54 & 205 \\
\hline PD28 & ATTAAAGATGGCTTTGGAG & AGAGTAGTGGCAGTGACCT & $(\mathrm{AAG}) 6$ & 54 & 52 & 240 \\
\hline PD33 & GGGGAACATGGTCTCATC & GGGCTTTCTCATAGGTGG & (TCT)5 & 60 & 58 & 139 \\
\hline PD35 & GAACCTTAGAGCTTGTGG & GACGAGTAATTCTCCTTT & $(\mathrm{TCA}) 5$ & 50 & 48 & 194 \\
\hline PD36 & GCATCTACCATTGGAGTG & ACAAAGCAAAGCGGATAC & $(\mathrm{TAC}) 5$ & 56 & 54 & 122 \\
\hline PD37 & GTGAGAATGGAGACTTTG & TCACCATCACTTTATCAG & $($ TAA $) 5$ & 54 & 52 & 149 \\
\hline PD38 & GGGAGTGAAGTTAAAGAA & TGAATCCAACACCGTATC & $(\mathrm{GCT}) 5$ & 54 & 52 & 140 \\
\hline PD40 & CTAGTACTTTTCTAAATTGGAC & TAATGGTTTTGGGTCACA & $(\mathrm{GAA}) 5$ & 54 & 52 & 108 \\
\hline PD49 & CAACTGGTCCCAATAATCC & GCTATGCCTCCTTCTACAAAA & $(\mathrm{ACA}) 5$ & 58 & 56 & 135 \\
\hline PD52 & CAGTTGAAATGCAAGGGTC & TGGAGTATCCAGGTGAGG & $(\mathrm{AAC}) 5$ & 58 & 56 & 189 \\
\hline PD54 & СTCTTCTTCTGCCTCTGC & AGTAGCAACAACCCTCAT & $(\mathrm{TCAA}) 5$ & 56 & 54 & 202 \\
\hline PD59 & АСССТТTСАСССТСТTСА & AATGTGGCTGCTCTGTTA & (TCT)8 & 56 & 54 & 130 \\
\hline
\end{tabular}

Initially 55 cultivated peanut genotypes were analyzed using the 33 primer pairs. Results showed that the polymorphism was very limited. Only one primer pair (PD59) could amplify polymorphic bands. In order to further evaluate the polymorphism of these 33 SSRs, seventeen cultivated peanut (from Wuhan national cultivated peanut germplasm resources) including var. fastigiata, var. hirsuta, var. hypogaea and var. vulgaris 
were analyzed (Table 1). Similarly, low polymorphism was revealed by these SSR markers and only $4(12.1 \%)$ primer pairs, F9, F13, PD20 and PD59, could amplify polymorphic bands (Figure 4).

For the 73 cultivated peanuts, primer pair PD59 could always amplify either one or both of two bands between 120 and $150 \mathrm{bp}$ (Figure 4). The upper band showed same size within cultivated peanut accessions tested. However, the lower band displayed varied size in different cultivars (Figure 4). The lower band of four cultivated peanuts, PI393531, Liaoning Silihong, Jinhua-1012 and Luhua-14 were recovered from the agarose gel for sequence analysis. The sequencing results were shown in Figure 5. Cultivars PI393531 from America and Luhua-14 had one TCT less than Liaoning Silihong which belonging to var. fastigiata and Jinhua-1012 which belongs to var. hypogaea.

\section{ACKNOWLEDGMENTS}

This work was supported by grants from Shandong Province (200701004, 2006BS06008, Z2002D06) and Shandong Academy of Agricultural Sciences (2006YBS001, 2007YCX001).

\section{REFERENCES}

BUROW, Mark D.; SIMPSON, Charles E.; STARR, James L. and PATERSON, Andrew H. Transmission genetics of chromatin from a synthetic amphidiploid to cultivated peanut (Arachis hypogaea L.): Broadening the gene pool of a monophyletic polyploid species. Genetics, October 2001, vol. 159 , no. 2 , p. 823-837.

CUC, Luu M.; MACE, Emma S.; CROUCH, Jonathan H.; QUANG, Vu D.; LONG, Trand D. and VARSHNEY, Rajeev K. Isolation and characterization of novel microsatellite markers and their application for diversity assessment in cultivated groundnut (Arachis hypogaea). BMC Plant Biology, 2008, vol. 8, no. 55.

DWIVEDI, S.L.; GURTU, S.; CHANDRA, S.; YUEJIN, W. and NIGAM, S.N. Assessment of genetic diversity among selected groundnut gemplasm. I: RAPD analysis. Plant Breeding, August 2001, vol. 120, no. 4, p. 345-349.

FERGUSON, M.E.; BUROW, M.D.; SCHULZE, S.R.; BRAMEL, P.J.; PATERSON, A.H.; KRESOVICH, S. and MITCHELL, S. Microsatellite identification and characterization in peanut (A. hypogaea L.). Theoretical and Applied Genetics, April 2004, vol. 108, no. 6, p. 10641070.

GAO, Dong; DU, Fei and ZHU, You-Yong. Lowbackground and high-resolution contracted silver-stained method in polyacrylamide gels electrophoresis. Hereditas (Beijing), June 2009, vol. 31, no. 6, p. 668-673.

GIMENES, M.A.; LOPES, C.R. and VALLS, J.F. M. Genetic relationship among Arachis species based on
AFLP. Genetics and Molecular Biology, 2002, vol. 25, no. 3, p. 349-353.

GIMENES, Marcos A.; HOSHINO, Andrea A.; BARBOSA, Andrea V.; PALMIERI, Dario A. and LOPES, Catalina R. Characterization and transferability of microsatellite markers of the cultivated peanut (Arachis hypogaea). BMC Plant Biology, 2007, vol. 7, no. 9.

HAN, Zhiguo; WANG, Changbiao; SONG, Xianliang; GUO, Wangzhen; GOU, Jinying; LI, Chunhong; CHEN, Xiaoya and ZHANG, Tianzhen. Characteristics, development and mapping of Gossypium hirsutum derived EST-SSRs in allotetraploid cotton. TAG Theoretical and Applied Genetics, February 2006, vol. 112, no. 3, p. 430439.

HE, Guohao and PRAKASH, Channapatna. Evaluation of genetic relationship among botanical varieties of cultivated peanut (Arachis hypogaea L.) using AFLP markers. Genetic Resources and Crop Evolution, August 2001, vol. 48 , no. 4 , p. $347-352$.

HE, Guohao; MENG, Ronghua; NEWMAN, Melanie; GAO, Guoquing; PITTMAN, Roy. N. and PRAKASH, Channapatna S. Microsatellites as DNA markers in cultivated peanut (Arachis hypogaea L.). BMC Plant Biology, 2003, vol. 3, no. 3.

HOLBROOK, C.C. and STALKER, H.T. Peanut breeding and genetic resources. Plant Breeding Reviews, 2003, vol. 22, p. 297-356.

LAGERCRANTZ, Ulf; ELLEGREN, Hans and ANDERSSON, Leif. The abundance of various polymorphic microsatellite motifs differs between plants and vertebrates. Nucleic Acids Research, March 1993, vol. 21, no. 5, p. 1111-1115.

LEAL-BERTIOLI, Soraya C.M.; JOSE, Ana Carolina V.F.; ALVES-FREITAS, Dione M.T.; MORETZSOHN, Márcio C.; GUIMARÃES, Patricia M.; NIELEN, Stephan; VIDIGAL, Bruna S.; PEREIRA, Rinaldo W.; PIKE, Jodie; FÁVERO, Alessandra P.; PARNISKE, Martin; VARSHNEY, Rajeev K. and BERTIOLI, David J. Identification of candidate genome regions controlling disease resistance in Arachis. BMC Plant Biology, 2009, vol. 9 , no. 112.

LI, Men-Jun; LI, Ai-Quin; XIA, Han; ZHAO, Chuan-Zhi; LI, Chang-Sheng; WAN, Shu-Bo; BI, Yu-Ping and WANG, Xing-Jun. Cloning and sequence analysis of putative type II fatty acid synthase genes from Arachis hypogaea L. Journal of Biosciences, June 2009, vol. 34, no. 2, p. 227-238.

LI, Meng-Jun; XIA, Han; ZHAO, Chuan-Zhi; LI, Ai-Qi; LI, Chang-Sheng; BI, Yu-Ping; WAN, Shu-Bo and WANG, Xing-Jun. Isolation and characterization of putative acetyl-CoA carboxylases in Arachis hypogaea L. 
Plant Molecular Biology Reporter, March 2010, vol. 28, no. 1, p. 56-58.

LIANG, Xuanqiang; CHEN, Xiaoping; HONG, Yanbin; LIU, Haiyan; ZHOU, Guiyuan; LI, Shaoxiong and GUO, Baozhu. Utility of EST-derived SSR in cultivated peanut (Arachis hypogaea L.) and Arachis wild species. BMC Plant Biology, 2009, vol. 9, no. 35.

MORETZSOHN, M.C.; LEOI, L.; PROITE, K.; GUIMARÃES, P.M.; LEAL-BERTIOLI, S.C.M.; GIMENES, M.A.; MARTINS, W.S.; VALLS, J.F.M.; GRATTAPAGLIA, D. and BERTIOLI, D.J. A microsatelite-based, gene-rich linkage map for the AA genome of Arachis (Fabaceae). TAG Theoretical and Applied Genetics, October 2005, vol. 111, no. 6, p. 10601071.

MURRAY, M. and THOMPSON, W. Rapid isolation of high-molecular weight plant DNA. Nucleic Acids Research, 1980, vol. 8, no.19, p. 4321-4325.

PROITE, Karina; LEAL-BERTIOLI, Soraya C.M.; BERTIOLI, David J.; MORETZSOHN, Márcio C.; DA SILVA, Felipe R.; MARTINS, Natalia F. and GUIMARÃES, Patricia M. ESTs from a wild Arachis species for gene discovery and marker development. BMC Plant Biology, 2007, vol. 7, no. 7.

SIMPSON, C.E.; STARR, J.L.; NELSON, S.C.; WOODARD, K.E. and SMITH, O.D. Registration of TxAG-6 and TxAG-7 peanut germplasm. Crop Science, November 1993, vol. 33, no. 6, p. 1418.

SIMPSON, C.E. and STARR, J.L. Registration of COAN peanut. Crop Science, May 2001, vol. 41, no. 3, p. 918.

STALKER, H.T. and BEUTE, M.K. Registration of four leaf spot resistant peanut germplasm lines. Crop Science, September 1993, vol. 33, p. 1117.

SUBRAMANIAN, V.; GURTU, S.; NAGESWARA RAO, R.C. and NIGAM, S.N. Identification of DNA polymorphism in cultivated groundnut using random amplified polymorphic DNA (RAPD) assay. Genome, August 2000, vol. 43, no. 4, p. 656-660.

TALLURY, S.P.; HILU, K.W.; MILLA, S.R.; FRIEND, S.A.; ALSAGHIR, M.; STALKER, H.T. and QUANDT, D. Genomic affinities in Arachis section Arachis (Fabaceae): molecular and cytogenetic evidence. Theoretical and Applied Genetics, November 2005, vol. 111, no. 7, p. 12291237.

WANG, Z.; WEBER, J.L.; ZHONG, G. and TANKSLEY, S.D. Survey of plant short tandem DNA repeats. Theoretical and Applied Genetics, April 1994, vol. 88, no. 1, p. 1-6.
WANG, X.J.; SU, L.; QUAN, X.Q.; SHAN, L.; ZHANG, H.T. and BI Y.P. Peanut (Arachis hypogaea L.) EST sequencing, gene cloning an Agrobacteria-mediated transformation. In: International groundnut conference on groundnut Aflatoxin and genomics. $\left(5^{\text {th }}-9^{\text {th }}\right.$ November, 2006, Guangzhou, China). Abstracts, 2006. p. 59. 